\title{
DETECÇÃO DE ADULTERAÇÕES EM PRODUTOS ALIMENTARES CONTENDO LEITE E/OU PROTEÍNAS LÁCTEAS
}

Ana Cristina A. Veloso

Instituto Politécnico de Bragança, Escola Superior Agrária, Quinta de Sta. Apolónia, Apartado 172, 5300 Bragança - Portugal

Natércia Teixeira

IBMC/Serviço de Bioquímica, Faculdade de Farmácia da Universidade do Porto, R. Aníbal Cunha, 164, 4050 Porto - Portugal

Isabel M.P.L.V.O. Ferreira* e Margarida A. Ferreira

CEQUP/ Serviço de Bromatologia, Faculdade de Farmácia da Universidade do Porto, R. Aníbal Cunha, 164 - 4050 Porto Portugal

Recebido em 16/7/01; aceito em 22/10/01

\begin{abstract}
DETECTION OF ADULTERATIONS IN FOOD PRODUCTS CONTAINING MILK AND/OR MILK PROTEINS. A critical review of the most relevant analytical methodologies for quality and authenticity control of dairy products and foods containing milk proteins is presented. Chromatographic, electrophoretic and immunological methods are used for: detection of cow's milk in ewe and goat milks, detection of whey added to milk, detection of caseins and/or whey proteins in non-lactic foods and study compounds resulting from milk proteins degradation. Techniques based on polimerase chain reaction are also suitable for detection of cow's milk on cheeses of ewe and goat milks.
\end{abstract}

Keywords: milk proteins; authenticity; analytical methods.

\section{INTRODUÇÃO}

A autenticidade dos alimentos tornou-se um problema global. É cada vez mais importante detectar a introdução no mercado de produtos fraudulentamente rotulados e de produtos de qualidade inferior, quer por razões econômicas, quer por razões de saúde pública. As adulterações em produtos alimentares contendo leite e/ou proteínas lácteas são relativamente frequentes e diversificadas, incluindo: $(i)$ adição de leite de vaca ao leite de ovelha e/ou cabra para a preparação de queijo; (ii) a incorporação de proteínas do soro na produção de queijos; (iii) a adição de caseínas, ou proteínas do soro a produtos alimentares, particularmente nos derivados de carne.

As flutuações sazonais na disponibilidade do leite de cabra e de ovelha e o preço mais elevado comparativamente ao leite de vaca são um incentivo para que os produtores de queijo adulterem os queijos tradicionais, de leite de cabra e de ovelha, com leite de vaca e proteínas do soro ${ }^{1-4}$. Deste modo, a possibilidade de determinar a matéria prima (tipo de leite) que foi utilizada na produção de queijos, tem grande importância, não só para garantir a genuinidade dos queijos com denominação de origem, e dos queijos fabricados com leites puros, mas também na determinação das percentagens de leite em queijos de mistura. Por outro lado, a incorporação de proteínas do soro em queijos aumenta o rendimento de produção, podendo assim ser utilizadas para substituir a gordura do leite dando origem a queijo de baixo teor de gordura ${ }^{5}$. A adição fraudulenta destas proteínas é normalmente detectada e quantificada pela determinação do glicomacropéptídeo. Este polipeptídeo sendo um componente específico do soro obtido da coagulação do leite pela renina, deverá estar ausente no leite ${ }^{6,7}$.

Um outro tipo de fraude que deverá ser detectado é a presença de produtos em desacordo com a rotulagem. Por exemplo, o consumo

*e-mail: bromato@ff.up.pt de produtos que contenham leite e este não seja declarado na rotulagem, poderá causar reações alérgicas, em indivíduos sensíveis a esse produto. As proteínas do soro e as caseínas são frequentemente adicionadas a produtos alimentares devido às suas propriedades agregantes. Assim, por razões éticas e econômicas, torna-se imperativo o desenvolvimento de métodos sensíveis para a detecção dos vários tipos de leites em produtos lácteos e não lácteos.

A avaliação da qualidade dos produtos lácteos deverá também incluir a detecção de compostos resultantes da degradação das proteínas. Por exemplo, a detecção de peptídeos presentes em leite UHT (Ultra-High-Temperature) recentemente processado poderá indicar que foi obtido a partir de leite de qualidade duvidosa. Por outro lado, a formação de peptídeos durante o armazenamento de produtos de longa duração, poder-se-á dever à presença de enzimas termicamente resistentes, que frequentemente provocam deterioração da qualidade desses produtos. Poder-se, também, analisar o grau de desnaturação das proteínas do soro, para avaliar a severidade do tratamento térmico utilizado, uma vez que este pode levar a uma importante perda da qualidade nutricional ${ }^{7,8}$.

Neste trabalho de revisão serão abordadas diferentes metodologias analíticas utilizadas na avaliação da qualidade e detecção de adulterações em produtos alimentares contendo leite e/ou proteínas lácteas.

\section{DETECÇÃO DE MISTURAS DE LEITE DE VACA, OVELHA E CABRA}

Com o objetivo de garantir a genuinidade dos queijos que têm leite de ovelha ou cabra como ingredientes, têm sido identificados alguns marcadores de autenticidade, químicos e biológicos, utilizando diferentes metodologias analíticas bem estabelecidas e validadas. No entanto, devido à grande variedade de queijos com diferentes características microbiológicas e bioquímicas e devido aos diferentes fatores que podem afetar o processo de maturação, os resultados obtidos para um dado tipo de queijo, podem não ser aplicados a outra variedade. 
Num trabalho de revisão publicado pela FIL (Fédération Internationale de Laiterie), Ramos ${ }^{9}$ divide estas metodologias analíticas em dois grupos, um baseado na determinação da composição em gordura, e outro na composição em proteínas do leite.

Os métodos baseados na composição em gordura utilizam geralmente ou os índices de ácidos graxos voláteis solúveis e insolúveis, em particular o índice de Polenske ${ }^{10}$ ou métodos cromatográficos, utilizados para determinar a composição em ácidos graxos. Para a análise das frações de proteínas podem igualmente ser utilizados métodos cromatográficos. No entanto, neste campo os métodos eletroforéticos e imunológicos têm-se mostrado mais vantajosos.

Mais recentemente, a técnica de PCR (Polimerase chain reaction), ao tornar possível localizar um pequeno fragmento de DNA numa complexa mistura de moléculas mais ou menos fragmentadas e replicá-lo milhões de vezes, permitindo a sua posterior identificação, tem contribuído para a identificação de espécies componentes em diferentes produtos alimentares ${ }^{11} \mathrm{e}$ inclusive no leite e no quei$\mathrm{jo}^{4,12,13}$.

\section{Métodos cromatográficos}

A cromatografia gasosa é uma das técnicas utilizadas no estudo da composição em gordura em queijos maturados, uma vez que com exceção dos queijos maturados com fungos, poucas mudanças têm lugar na composição em gordura durante o processo de maturação ${ }^{14,15}$. Contudo, esta técnica não é eficiente quando se usa como adulterante leite desnatado.

A gordura do leite das três espécies (vaca, ovelha e cabra) contém elevada proporção de ácidos voláteis com número par de átomos de carbono. No entanto, o leite de ovelha e cabra contêm teores mais elevados de ácido capróico $\left(\mathrm{C}_{6}\right)$, caprílico $\left(\mathrm{C}_{8}\right)$, cáprico $\left(\mathrm{C}_{10}\right)$ e láurico $\left(\mathrm{C}_{12}\right)$. As misturas podem ser detectadas com base nestas diferenças, desde que as proporções não sejam inferiores a $15-20 \%$, pois é necessário ter em conta o intervalo de variação da composição em ácidos graxos, devido a fatores genéticos e ambientais. A relação entre alguns ácidos graxos, especificamente, $\mathrm{C}_{4} / \mathrm{C}_{6}+\mathrm{C}_{8}$ e $\mathrm{C}_{12} / \mathrm{C}_{10}$, entre outras, apresenta menores intervalos de variação que os ácidos graxos individuais ${ }^{16}$.

Técnicas de cromatografia líquida (RP-HPLC - Reversed-phase High Pressure Liquid Chromatography), com detecção por ultravioleta e fluorescência, foram igualmente utilizadas para a identificação de leite de vaca em leite e queijo de outras espécies, através da análise da composição em $\beta$-lactoglobulina $\mathrm{A}$ bovina ${ }^{17}$. Os autores conseguiram detectar quantidades de $2 \%$ de leite de vaca em amostras de queijos com 2 anos de maturação.

Kaminarides e Anifantakis ${ }^{18}$ conseguiram a separação das diferentes frações de caseínas que compõem o leite de vaca, ovelha e cabra por HPLC com uma coluna de troca aniónica (P.L.-SAX $8 \mu$ 1000 A) e detecção no UV a $280 \mathrm{~nm}$. Os leites de ovelha e cabra apresentam perfis cromatográficos relativamente parecidos, mas que diferem consideravelmente do leite de vaca. A eluição da $\alpha_{\mathrm{s} 1}$-caseína bovina ocorre mais tarde que a das $\alpha_{\mathrm{s} 1}$-caseínas caprina e ovina, utilizando-se as mesmas condições cromatográficas. Deste modo, é possível detectar e quantificar a presença de leite de vaca em leite de ovelha e cabra. A quantidade de leite de vaca adicionado em amostras adulteradas poderá assim ser calculada por integração da área dos picos de $\alpha_{\mathrm{s} 1}$-caseina bovina, usando uma curva padrão preparada previamente com amostras adulteradas de composição conhecida.

\section{Métodos eletroforéticos}

Entre os métodos fisico-químicos utilizados para estudar misturas de leite de ovelha, cabra e vaca, as técnicas eletroforéticas apre- sentam elevada sensibilidade (comparáveis aos métodos biológicos) e não requerem reagentes especiais, nem equipamento muito dispendioso.

Inicialmente, os métodos eletroforéticos detectavam as misturas de leite baseando-se na mobilidade superior da $\alpha_{\mathrm{s} 1}$-caseina do leite de vaca. No entanto, têm surgido técnicas mais sofisticadas, tais como a eletroforese em géis de poliacrilamida contendo ureia, que permitem a diferenciação das proteínas do leite de vaca do leite de ovelha e cabra, a partir da $\gamma$-caseinas bovinas. Apesar destas técnicas eletroforéticas serem muito úteis na análise de misturas de leite, a detecção é mais difícil em queijos com proteólise extensa. Diversos fatores, como o $\mathrm{pH}$, tipo de coagulante, quantidade de soro que permanece na coalhada e o uso de culturas "starter", pode afetar a proteólise das caseínas.

Encontram-se resumidos na Tabela 1 alguns métodos eletroforéticos aplicados na detecção de adulterações em leite.

A adição de leite de vaca em queijos de ovelha foi quantificada por esta metodologia por Amigo et al. ${ }^{20}$. Estes autores utilizaram a análise eletroforética das proteínas do soro para detectarem a adulteração, e verificaram que a razão entre a $\beta$-lactoglobulina A e B e a albumina sérica bovina forneceu resultados muito precisos. Utilizando como corante nitrato de prata, foi possível a detecção de quantidades de leite de vaca da ordem de $1 \%$ nos queijos. Este método tem a vantagem de permitir analisar as proteínas do soro que são menos susceptíveis que as caseínas à proteólise. Deve ser ressaltado, que embora as proteínas do soro estejam presentes em concentrações muito reduzidas, estas permanecem inalteradas após 5 meses de maturação dos queijos. No entanto, os autores verificaram que o aquecimento do leite de vaca a $90^{\circ} \mathrm{C}$ durante 30 minutos desnatura as proteínas do soro, não permitindo detectar pequenas concentrações (1 a 10\%) de leite de vaca adicionado. Estes autores verificaram ainda que os agentes coagulantes vegetais exerciam nas proteínas do soro, uma ação proteolítica superior ao do coalho animal, embora não influenciassem o nível de detecção. O tipo de pressão exercida também não afeta o nível de detecção. Este procedimento é simples e de baixo custo.

Mayer e Hörtner ${ }^{21}$ utilizaram uma eletroforese em gradiente em gel de poliacrilamida para separar a $\beta$-caseína e assim determinar a presença das caseínas bovinas em produtos lácteos.

Utilizando a técnica de SDS-PAGE (Polyacrylamide Gel Electrophoresis in Sodium Dodecyl Sulfate) é possível quantificar as caseínas e as proteínas do soro em leite processado líquido e em pó $^{24}$. Este método poderá permitir a detecção de adulterações do leite por concentrados de proteínas do soro ou leite desnatado em pó.

O método de SDS-PAGE não só é apropriado para a determinação das proteínas do soro e caseínas nos produtos lácteos, como também, tem sido utilizado para estudar e caracterizar a proteosepeptona ${ }^{25}$.

Recentemente a técnica de SDS-PAGE foi usada para determinar a composição das proteínas do soro em leite de cabra e de ovelha. A quantificação das diferentes proteínas foi feita por um sistema de análise de imagem ${ }^{23}$.

A focagem isoelétrica ( $\mathrm{pH} 4$ a 9) tem sido utilizada como primeira eletroforese, seguida por uma eletroforese em gel de poliacrilamida com SDS ou ureia para separar as caseínas do leite ${ }^{26}$. Estes autores relatam que com esta técnica, é possível separar não só as caseínas como também a para-k-caseína, a $\beta$-lactoglobulina e $\alpha$ lactoalbumina.

A eletroforese capilar tem provado ser uma técnica eficiente na análise das proteínas do leite e na avaliação da qualidade dos produtos lácteos. Existem diversos trabalhos que descrevem a sua utilização na análise de polimorfismos das proteínas, na avaliação da extensão dos tratamentos térmicos, na detecção de adulterações e de 
Tabela 1. Métodos eletroforéticos em gel aplicados na detecção de adulterações em leite e derivados

\begin{tabular}{|c|c|c|c|c|}
\hline Composto & Método & Condições de análise & Aplicação & Referência \\
\hline Caseínas & $\begin{array}{l}\text { Eletroforese } \\
\text { em gel de } \\
\text { poliacrilamida }\end{array}$ & $\begin{array}{l}\text { - gel de poliacrilamida 9\% } \\
\text { - coloração: azul de Coomassie G250, } 15 \mathrm{~h} \\
\text { - Quantificação por densitometria a } 550 \mathrm{~nm}\end{array}$ & $\begin{array}{l}\text { Detecção da adição de leite } \\
\text { de vaca a leite de cabra } \\
\text { pasteurizado }\end{array}$ & (19) \\
\hline Proteínas do soro & $\begin{array}{l}\text { Eletroforese } \\
\text { em gel de } \\
\text { poliacrilamida }\end{array}$ & $\begin{array}{l}\text { - tampão de electroforese: tampão } \\
\text { Tris-glicina a pH } 8,3 \\
\text { - coloração: azul de Coomassie G250 e R250 } \\
\text { e nitrato de prata } \\
\text { - quantificação por densitometria a } 600 \mathrm{~nm}\end{array}$ & $\begin{array}{l}\text { Detecção de leite de vaca } \\
\text { adicionado a queijos de } \\
\text { leite de ovelha }\end{array}$ & (20) \\
\hline$\beta$-caseína & $\begin{array}{l}\text { Eletroforese } \\
\text { em gel de } \\
\text { poliacrilamida }\end{array}$ & $\begin{array}{l}\text { - tampão superior: ACES } 40 \mathrm{mM}, \mathrm{pH} 6,8 \\
\text { - tampão inferior: piridina } 200 \mathrm{mM}, \mathrm{pH} 5,2 \\
\text { - coloração: azul de Coomassie G250 } \\
\text { - quantificação por densitometria a } 629 \mathrm{~nm}\end{array}$ & $\begin{array}{l}\text { Detecção de caseínas bovinas } \\
\text { em leite e produtos derivados }\end{array}$ & $(21)$ \\
\hline $\begin{array}{l}\text { Caseínas, proteínas do } \\
\text { soro, proteínas da } \\
\text { membrana dos glóbulos } \\
\text { de gordura }\end{array}$ & $\begin{array}{l}\text { Eletroforese } \\
\text { em gel de } \\
\text { poliacrilamida } \\
\text { com SDS }\end{array}$ & $\begin{array}{l}\text { - coloração: azul de Coomassie R } \\
\text { - quantificação por densitometria a } 600 \mathrm{~nm}\end{array}$ & $\begin{array}{l}\text { Detecção de adulterações do } \\
\text { soro de leite coalhado em pó }\end{array}$ & (22) \\
\hline Proteínas do soro & $\begin{array}{l}\text { Eletroforese } \\
\text { em gel de } \\
\text { poliacrilamida } \\
\text { com SDS }\end{array}$ & $\begin{array}{l}\text { - coloração: azul de Coomassie R250 } \\
\text { - quantificação por tecnologia de análise } \\
\text { de imagem }\end{array}$ & $\begin{array}{l}\text { Determinação da composição } \\
\text { das proteínas do soro em leite } \\
\text { de cabra e ovelha }\end{array}$ & (23) \\
\hline
\end{tabular}

Tris - tris(hidroximetil)aminometano; ACES - ácido N-(2-acetamido)-2-aminoetanosulfónico; SDS - dodecilsulfato de sódio

peptídeos derivados das proteínas durante a proteólise no leite e seus derivados ${ }^{7}$. Os tipos de eletroforese capilar mais utilizados nestas análises são a eletroforese capilar de zona (capillary zone electrophoresis - CZE), a eletroforese capilar em gel (capillary gel electrophoresis - CGE) e a focagem isoeléctrica capilar (capillary isoelectric focusing - CIEF). Na Tabela 2 são apresentados alguns trabalhos que aplicam esta técnica na detecção de adulterações em produtos alimentares contendo leite e/ou proteínas lácteas.

A eletroforese capilar de zona foi utilizada na detecção dos diferentes tipos de leite em misturas de leite de vaca, ovelha e cabra ${ }^{2}$. Cada tipo de leite originou um perfil eletroforético típico, permitindo a sua identificação. $\mathrm{O}$ método desenvolvido por estes autores permitiu a detecção de $8 \%$ e $1 \%$ de leite de vaca adicionado a leite de ovelha ou cabra, respectivamente, de acordo com os diferentes tempos de migração da $\alpha_{\mathrm{s} 1}$-caseína de cada espécie. Por outro lado, Cartoni et al. ${ }^{29}$ utilizaram a mesma técnica para determinar a adulteração de produtos de leite de cabra com leite de vaca. A detecção e quantificação do leite de vaca foi obtida pela presença da alactoalbumina e $\beta$-lactoglobulina A e B. Estes autores conseguiram detectar $2 \%$ de leite de vaca em misturas dos dois tipos de leite e $4 \%$ em queijos. Com este método estes autores apenas conseguiram uma análise qualitativa de misturas de leite de vaca, cabra e ovelha e de misturas de leite de cabra e ovelha, devido à sobreposição dos picos referentes à $\alpha$-lactoalbumina do leite de cabra e ovelha.

\section{Métodos imunológicos}

Os ensaios imunológicos são frequentemente utilizados na indústria alimentícia para uma detecção qualitativa e quantitativa de componentes alimentares e contaminantes, tendo sido utilizados pela primeira vez no final dos anos 60. A sua aplicação inicial foi na detecção de proteínas específicas em concentrações muito baixas.

Estes primeiros ensaios baseavam-se em ensaios radioimunológicos desenvolvidos no campo da medicina, não sendo extensivamente utilizados devido à necessidade de utilização de marcadores radioativos. O desenvolvimento, no início dos anos 70, de ensaios imunoenzimáticos, onde os marcadores radioativos são substituídos por enzimas, eliminando os perigos associados com a técnica anterior, resulta numa maior aceitação destes ensaios aplicados a análises de alimentos. Além disso, a relativa simplicidade dos ensaios enzimáticos e a elevada sensibilidade, devido à especificidade das reações antígenio-anticorpo, associada a baixos custos e à utilização de equipamento não sofisticado, dão a estes métodos um grande potencial na indústria alimentícia.

As proteínas do soro são extremamente antigênicas e a sua determinação por técnicas imunológicas usuais como a imunodifusão radial, a "Rocket" eletroforese, método ELISA (Enzyme-Linked Immunosorbent Assay), e ensaios radioimunológicos não é complicada. A determinação das caseínas, apesar de bastante fiável, é mais difícil, uma vez que, estas proteínas são pouco antigênicas e encontram-se na forma de agregados ${ }^{26}$.

A imunoprecipitação em meio líquido foi a primeira técnica imunológica utilizada na detecção de leites, de diversas origens animais, em misturas lácteas ${ }^{30}$. É eficaz em leites crus e pasteurizados, mas não em leites esterilizados, em pó ou condensados. Para estes leites não é possível observar a reação de precipitação, porque os precipitados são pouco visíveis e desaparecem rapidamente após a sua formação.

Os métodos imunológicos em gel, em que se mistura o anticorpo em concentração conhecida no gel, são sensíveis e apresentam elevada reprodutibilidade. A técnica de imunodifusão dupla em géis de agarose foi utilizada pela primeira vez em 1974, e permitiu detectar $2,5 \%$ de leite de vaca em leite de cabra e ovelha ${ }^{31}$. Este método embora semi- -quantitativo, não é influenciado pela proteólise do queijo.

O teste COMIT para a identificação de leite de vaca (3-100\%) em leite de ovelha, utiliza anticorpos policlonais para as proteínas séricas do leite de vaca ${ }^{32}$. A diferença entre este e as técnicas de imunodifusão convencionais está na utilização de reagentes liofilizados em discos de papel de filtro, o que permite a sua difusão no gel. Além disso, os géis possuem um corante e uma concentração 
Tabela 2. Métodos de eletroforese capilar aplicada à análise das proteínas do leite

\begin{tabular}{|c|c|c|c|c|}
\hline Composto & Método & Condições de análise & Aplicação & Referência \\
\hline $\begin{array}{l}\alpha \text {-la, } \beta \text {-lg A e B, } \\
\alpha_{\mathrm{s}} \text {-caseínas e } \\
\beta \text {-caseína }\end{array}$ & $\begin{array}{l}\text { Eletroforese capilar } \\
\text { de zona }\end{array}$ & $\begin{array}{l}\text { - coluna não tratada de sílica fundida } \\
\text { - solvente de análise: tampão fosfato } \\
0,5 \mathrm{M}, \mathrm{pH} \text { 6-9, com e sem ureia } 4 \mathrm{M} \\
\text { - solvente da amostra: PBS, pH } 7 \\
\text { - injecção do leite sem tratamento da } \\
\text { amostra } \\
\text { - detecção UV a } 200 \mathrm{~nm}\end{array}$ & $\begin{array}{l}\text { Determinação da razão } \\
\beta \text {-caseína/ } \alpha \text {-la na } \\
\text { detecção de adulterações } \\
\text { do leite com leite em pó }\end{array}$ & (27) \\
\hline Glicomacro-péptídeo & $\begin{array}{l}\text { Eletroforese capilar } \\
\text { de zona }\end{array}$ & $\begin{array}{l}\text { - coluna capilar hidrofílica revestida de } \\
\text { sílica fundida } \\
\text { - solvente de análise: tampão citrato } \\
\text { com uréia } 6 \text { M e MHEC } 0,05 \%, \text { pH } 3 \\
\text { - detecção UV a } 214 \mathrm{~nm}\end{array}$ & $\begin{array}{l}\text { Detecção e quantificação } \\
\text { do glicomacropeptídeo } \\
\text { para detectar e estimar o } \\
\text { soro em pó, em leite e } \\
\text { soro de leite coalhado em pó }\end{array}$ & (28) \\
\hline $\begin{array}{l}\alpha \text { e } \beta \text {-caseínas, } \\
\text { proteínas do soro }\end{array}$ & $\begin{array}{l}\text { Eletroforese capilar } \\
\text { de zona }\end{array}$ & $\begin{array}{l}\text { - coluna capilar revestida de } \\
\text { sílica fundida } \\
\text { - solvente de análise: tampão citrato } \\
\text { de sódio } 20 \mathrm{mM} \text { com MHPC } 0,1 \% \\
\text { e ureia } 6 \mathrm{M} \\
\text { - detecção UV a } 214 \mathrm{~nm}\end{array}$ & $\begin{array}{l}\text { Separação das proteínas do } \\
\text { leite de diferentes espécies. } \\
\text { Detecção de leite de vaca } \\
\text { em leite de cabra e ovelha }\end{array}$ & (2) \\
\hline$\alpha-\operatorname{la}, \beta-\lg \mathrm{A}$ e B e BSA & $\begin{array}{l}\text { Eletroforese capilar } \\
\text { de zona }\end{array}$ & $\begin{array}{l}\text { - coluna não tratada de sílica fundida } \\
\text { - solvente de análise: tampão borato } \\
100 \mathrm{mM} \text { com sulfato de sódio } 30 \mathrm{mM} \text {, } \\
\text { pH } 8,2 \\
\text { - soro ácido injectado directamente } \\
\text { - detecção UV a } 214 \mathrm{~nm}\end{array}$ & $\begin{array}{l}\text { Quantificação das proteínas } \\
\text { do soro do leite durante o } \\
\text { armazenamento de leites UHT. } \\
\text { Comparação com HPLC. } \\
\text { Identificação da origem de } \\
\text { produtos resultantes da } \\
\text { proteólise }\end{array}$ & (8) \\
\hline$\alpha-\operatorname{la}$ e $\beta-\lg \mathrm{A}$ e $\mathrm{B}$ & $\begin{array}{l}\text { Eletroforese capilar } \\
\text { de zona }\end{array}$ & $\begin{array}{l}\text { - coluna capilar de metil-silanizada } \\
\text { - solvente de análise: tampão borato } \\
50 \mathrm{mM} \text {, pH 9,27 ou tampão borato } \\
120 \mathrm{mM}, \text { pH 9,2 } \\
\text { - detecção UV a } 200 \mathrm{~nm}\end{array}$ & $\begin{array}{l}\text { Análise qualitativa das } \\
\text { proteínas do soro de leite } \\
\text { de vaca e cabra. } \\
\text { Determinação do leite de } \\
\text { vaca em leite e queijo de cabra }\end{array}$ & (29) \\
\hline
\end{tabular}

MHEC - metilhidroxietilcelulose; PBS - cloreto de sódio $75 \mathrm{mM}$, fosfato de potássio $20 \mathrm{mM}$ e azida de sódio $0,01 \%$; MHPC metilhidroxipropilcelulose.

adequada de polietilenoglicol, o que permite uma visualização mais eficiente das linhas de precipitação antigénio-anticorpo.

As técnicas descritas apresentam alguns inconvenientes, particularmente, requerem muito tempo ou necessitam de uma grande quantidade de anticorpos purificados e são qualitativas ou semi-quantitativas. O desenvolvimento das técnicas imunoenzimáticas (ELISA) constituiu uma alternativa interessante, pois estas possuem boa reprodutibilidade e uma sensibilidade mais elevada que a dos métodos imunológicos em gel.

Diversos tipos de ELISA têm sido aplicados no doseamento das proteínas do soro e das caseínas, principalmente com o objetivo de detectar adulterações nos produtos lácteos. Alguns exemplos são apresentados na Tabela 3.

Dois métodos ELISA (indireto e em sanduiche), foram desenvolvidos por García et al. ${ }^{33,34}$ para detectar pequenas adulterações de leite de vaca no leite de ovelha. Em ambos foram utilizados anticorpos policlonais contra as proteínas do soro do leite de vaca, conjugados com biotina. Uma vez que a biotina é uma pequena molécula, a sua ligação aos anticorpos não prejudica a associação antígenio-anticorpo, mantendo a especificidade do anticorpo para o antígenio, o que poderá não acontecer quando uma enzima se fixa diretamente ao anticorpo. Por outro lado, a conjugação da biotina com anticorpos é um procedimento muito mais simples, originando produtos mais estáveis do que os complexos enzima-anticorpo.
No método de ELISA indireto foi possível detectar leite de vaca cru em leite de ovelha, embora a sensibilidade do método fosse baixa, dado que não permitiu a quantificação de pequenas percentagens de leite de vaca $(1-10 \%)$ adicionadas ${ }^{33}$. As proteínas do soro desnaturam mais facilmente pelo calor que as caseínas. Assim, a sua desnaturação térmica poderá diminuir a sensibilidade deste método para a detecção de leite de vaca em leite de ovelha. Os autores analisaram leite de vaca pasteurizado e UHT, retirados do mercado, e obtiveram resultados semelhantes aos obtidos com amostras de leite cru. O mesmo não aconteceu com leites esterilizados, onde obtiveram uma diminuição de $25 \%$ de antigenicidade das proteínas do soro $^{33}$.

No método de ELISA em sanduíche, foi possível detectar e quantificar quantidades bem definidas (1-30\%) de leite de vaca adicionadas a leite de ovelha. Este método é mais sensível do que o método ELISA indireto na detecção e quantificação de pequenas quantidades (1-10\%) de leite de vaca adicionado a leite de ovelha. Contudo, com o ELISA em sanduíche não foi possível detectar a adição de leite de vaca UHT e esterilizado. A resposta obtida com leite de vaca pasteurizado foi $50 \%$ mais baixa que a obtida com leite de vaca $\mathrm{cru}^{34}$.

O método de ELISA indireto desenvolvido por Haza et $_{\text {al. }}{ }^{3}$ utiliza anticorpos monoclonais contra a $\alpha_{\mathrm{s} 2}$-caseína do leite de cabra. Este método foi utilizado para detectar e quantificar quantidades de- 
Tabela 3. Métodos imunológicos de ELISA aplicados às proteínas do leite

\begin{tabular}{|c|c|c|c|}
\hline MÉTODO & ANTIGÉNIO & APLICAÇÃO & REFERÊNCIA \\
\hline ELISA (indirecto) & Proteínas do soro do leite de vaca & $\begin{array}{l}\text { Detecção de leite de vaca adicionado } \\
\text { a leite de ovelha }\end{array}$ & (33) \\
\hline ELISA (sanduiche) & Proteínas do soro do leite de vaca & $\begin{array}{l}\text { Detecção e quantificação de leite de } \\
\text { vaca adicionado a leite de ovelha }\end{array}$ & (34) \\
\hline ELISA (indirecto) & $\alpha_{\mathrm{s} 2}$-caseína de leite de cabra & $\begin{array}{l}\text { Detecção de leite de cabra adicionado } \\
\text { a leite de ovelha }\end{array}$ & (3) \\
\hline ELISA (competitivo indirecto) & $\beta$-lg bovina nativa e desnaturada & $\begin{array}{l}\text { Detecção de proteínas do leite de vaca } \\
\text { nativas e desnaturadas em queijos de } \\
\text { ovelha e cabra }\end{array}$ & (1) \\
\hline ELISA & $\gamma$-caseína bovina & $\begin{array}{l}\text { Detecção de leite de vaca e caseinatos } \\
\text { adicionados a queijo de cabra e ovelha }\end{array}$ & (35) \\
\hline
\end{tabular}

finidas $(0,5-15 \%)$ de leite de cabra adicionado a leite de ovelha. O limite de detecção situa-se entre 0,5 e $1 \%$ de leite de cabra adicionado. Estes autores analisaram também leite de cabra sujeito a diferentes tratamentos térmicos. Os resultados obtidos indicam que a antigenicidade da caseína do leite de cabra não é afetada por estes tratamentos, permitindo a sua detecção e quantificação.

Beer et al. ${ }^{1}$ e Richter et $a l .{ }^{35}$ descrevem dois métodos ELISA competitivos indiretos para detectar leite de vaca adicionado a queijo de cabra e ovelha. Os primeiros autores utilizam anticorpos policlonais contra a $\beta$-lactoglobulina bovina nativa e desnaturada, enquanto os segundos utilizam anticorpos policlonais contra a $\gamma$ caseína bovina. No primeiro método foi possível detectar $100 \mathrm{ng} / \mathrm{ml}$ de $\beta$-lactoglobulina bovina nativa e desnaturada que equivale a 0,1 $0,2 \%$ de leite de vaca adicionado nos queijos de cabra e ovelha, sendo assim possível a detecção de adulterações. No método desenvolvido por Richter et al. ${ }^{35} \mathrm{o}$ limite de detecção conseguido foi de $0,1 \%$ de leite de vaca e caseinatos adicionados. Os autores concluíram ainda que este método não poderá ser aplicado à detecção de leite de vaca em queijos de leite de búfalo, uma vez que, a $\gamma$-caseína deste leite está relacionada com a $\gamma$-caseína bovina, ligando-se de modo semelhante aos anticorpos utilizados.

Os métodos ELISA são cada vez mais utilizados na análise de produtos alimentícios devido à sua sensibilidade, baixo custo e reduzido tempo de análise podendo vir a desempenhar um importante papel no controle da autenticidade dos produtos lácteos.

\section{Reação em cadeia da polimerase (PCR)}

O leite proveniente de glândulas mamárias saudáveis contém um certo número de células somáticas (100.000-500.000/ml para a vaca), predominantemente leucócitos, $2 \%$ dos quais se acredita serem provenientes das células epiteliais ${ }^{36}$. A técnica de reação em cadeia da polimerase (PCR) baseia-se na análise de DNA, permitindo detectar e amplificar pequenos fragmentos de DNA. Esta técnica tem sido aplicada na indústria de lacticínios, principalmente para detectar contaminações microbiológicas, contudo, o leite é também um substrato adequado para as análises por $\mathrm{PCR}^{4,12,13}$.

É possível extrair DNA do leite e de produtos lácteos processados como o queijo e utilizar este DNA genómico como substrato para amplificação por PCR do DNA específico da caseína. Nesta técnica são utilizados primers codificando parte da sequência do gene da $\beta$-caseína, para detectar o correspondente DNA no leite e queijo. Os fragmentos de DNA amplificados são separados por eletroforese em gel de agarose corado com brometo de etídio. O fragmento do gene da $\beta$-caseína $(253,247 \mathrm{pb})$ foi observado no leite de vaca, ovelha e cabra, assim como no leite em pó, no leite condensado bovino e em queijos. A detecção de leite de vaca nos leites e queijos de ovelha e cabra foi possível com base na diferenciação de tamanho dos fragmentos de PCR, os de bovino apresentaram 253 pb enquanto que os de ovino/caprino apresentaram $247 \mathrm{pb}^{4,12,13}$.

O DNA extraído pode ser usado também em análises mais complexas, como análises de restrição enzimática específica. A identificação de locais específicos de restrição enzimática, localizados exclusivamente no produto de PCR de ovino/caprino, permitiu uma detecção mais exata após digestão. Obtiveram-se dois fragmentos de 66 e 181 pb após o uso de enzimas de restrição Alu I ou 87 e 160 pb para a enzima Ava II. Após a adição de leite de vaca ao leite de cabra, Plath et al. ${ }^{4}$ obtiveram uma banda adicional correspondendo ao produto por hidrolisar do PCR de bovino (253pb). Deste modo, foi possível estabelecer um ensaio semi-quantitativo, com um limite de detecção de $0,5 \%$ de leite de vaca em queijos preparados com leite de ovelha e de cabra.

\section{Espectrometria de massa}

A espectrometria de massa tem sido utilizada para determinar a massa molecular das proteínas do leite de vaca ${ }^{48}$, ovelha ${ }^{49}$ e cabra ${ }^{50}$, assim como na identificação de variantes genéticas ${ }^{51,52}$, alterações na composição dos aminoácidos e modificações como fosforilaçãa $0^{53} \mathrm{e}$ glicosilação ${ }^{53}$.

O estudo das proteínas do leite de vaca utilizando a técnica de HPLC com detecção por espectrometria de massa (MS) forneceu informações importantes para a caracterização das caseínas ${ }^{52}$ e outras proteínas do leite ${ }^{48}$. Trujillo e colaboradores aplicaram igualmente a espectrometria de massa em combinação com HPLC, para a separação em linha, detecção e estudo da composição das proteínas de leite de cabra $^{49}$ e de ovelha ${ }^{50}$. As proteínas do soro que não foi possível resolver por HPLC-MS, foram purificadas por FPLC (fast preparative liquid chromatography) e analisadas por espectrometria de massa via análise por injecção em fluxo (FIA) ${ }^{49,50}$.

As metodologias descritas permitem caracterizar cada um dos tipos de leite, assim como o estudo de processos proteolíticos no leite.

\section{DETECÇÃO DA INCORPORAÇÃO DE SORO EM LEITE}

A adição fraudulenta de soro ao leite é normalmente detectada e quantificada pela determinação do glicomacropeptídeo, que resulta 
da quebra da ligação peptídica da k-caseína entre os aminoácidos 105-106 Phe-Met. Desta cisão forma-se a para-k-caseína (1-105) que permanece nas micelas de caseína e o glicomacropeptídeo (106169) que fica no soro.

O glicomacropéptídeo é geralmente quantificado por métodos cromatográficos, particularmente a cromatografia de exclusão molecular ${ }^{37}$. HPLC em fase reversa ${ }^{38}$ e cromatografia de troca iónica, quer catiónica ${ }^{39}$, quer aniónica ${ }^{40}$. A eletroforese capilar de zona com uma coluna hidrofílica de sílica fundida ${ }^{28}$ foi também utilizada com sucesso na detecção e quantificação do glicomacropetídeo para detectar e quantificar o soro em leite.

\section{DETECÇÃO DE CASEÍNAS E/OU PROTEÍNAS DO SORO EM PRODUTOS ALIMENTARES NÃO LÁCTEOS}

As caseínas podem ser facilmente purificadas através da precipitação no ponto isoelétrico ou por coagulação pela renina. Desde os anos 60 que as caseínas vêm sendo utilizadas na indústria alimentícia por proporcionarem textura e corpo aos alimentos, funcionarem como emulsificantes e reterem água. São frequentemente utilizadas em alimentos como produtos de confeitaria (bolos, pão, biscoitos), bebidas (lácteas e não lácteas), sopas, vegetais, carnes, sobremesas (mousses e gelados), cremes de café, etc.

$\mathrm{O}$ interesse pelas proteínas do soro é mais recente. O desenvolvimento, nos anos 70 , de processos de ultrafiltração facilitou a sua purificação, observando-se uma crescente aplicação destas proteínas na indústria alimentícia. Devido às suas propriedades emulsificantes e gelificantes e à viscosidade e solubilidade, a sua utilização é relevante em bebidas, produtos lácteos, cárneos, confeitaria, sopas, molhos, condimentos e produtos dietéticos ${ }^{41}$.

No entanto, a incorporação de caseínas e proteínas do soro nos alimentos deve ser declarada na rotulagem. O consumo de produtos que contenham leite e que não seja mencionado na rotulagem, pode causar reações alérgicas em indivíduos sensíveis. Para detectar a presença de proteínas do leite em alimentos não lácteos, particularmente em produtos cárneos, utilizam-se igualmente métodos eletroforéticos, imunológicos e cromatográficos ${ }^{42}$. Estes métodos apresentam alguns problemas de sensibilidade e reprodutibilidade em alimentos esterilizados.

\section{DETECÇÃO DE COMPOSTOS RESULTANTES DA DEGRADAÇÃO DAS PROTEÍNAS DO LEITE}

Modificações tais como desnaturação e proteólise, comuns na manufactura de muitos lacticínios levam à formação de novos compostos, incluindo peptídeos e aminoácidos. As proteólises incontroladas ou prolongadas (químicas ou enzimáticas) podem resultar na formação de peptídeos amargos. Geralmente, este sabor amargo está relacionado com o conteúdo em aminoácidos hidrofóbicos. Informações sobre a ocorrência destes compostos derivados são úteis para avaliar a qualidade do processamento e possíveis adulterações.

O estudo, por eletroforese capilar e por HPLC, das modificações que ocorrem na fração proteica de leites submetidos a tratamento UHT contribuiu decisivamente para controlar a qualidade deste produto. Por um lado, é possível avaliar a severidade do tratamento térmico através do estudo da desnaturação das proteínas do soro ${ }^{8,43,44}$. Por outro lado, a presença de peptídeos no leite recentemente produzido indica que este foi obtido a partir de leite cru de baixa qualidade, e a formação de peptídeos durante o armazenamento do leite UHT, pode ser uma indicação da presença de enzimas resistentes ao calor $^{45}$.

A técnica de eletroforese capilar permite a diferenciação entre peptídeos produzidos pela ação da plasmina e os que resultam das enzimas proteolíticas das bactérias psicotróficas ${ }^{8}$. Deste modo, fornece informação sobre a qualidade do leite cru e da tecnologia utilizada. Também permite avaliar a severidade do tratamento térmico a que o leite foi submetido.

Uma outra reacção de interesse em leites aquecidos é a reacção da lactose com os resíduos de lisina das proteínas. As reacções de Maillard observadas provocam a formação de lactulosil-lisina. A hidrólise deste produto origina a furosina, cuja quantificação é uma boa indicação da intensidade do tratamento térmico, assim como, uma medida da desnaturação proteica e perda de lisina. A sua presença no leite pode ainda fornecer uma informação complementar sobre a qualidade do leite, pois permite saber se foi adicionado leite em pó reconstituído ao leite líquido ${ }^{7,46,47}$.

\section{CONCLUSÕES}

O controlo de qualidade do leite e derivados deve tornar-se cada vez mais rigoroso e frequente. A indústria de lacticínios e as entidades responsáveis por assegurar a autenticidade destes produtos, necessitam ter à sua disposição meios que possam dar respostas precisas em tempo real, ao longo das várias etapas de fabricação e comercialização, minimizando os custos decorrentes de qualquer anomalia que possa surgir.

A cromatografia, a eletroforese e os ensaios imunológicos têm sido as técnicas mais adequadas para avaliar a qualidade e autenticidade dos produtos alimentares contendo leite e/ou proteínas lácteas. $\mathrm{O}$ desenvolvimento de cromatografias rápidas, FPLC e HPLC, e de eletroforese capilar, abriu novas perspectivas para a diminuição dos tempos de análise. Mais recentemente, com a técnica de PCR também se têm obtido resultados promissores. $\mathrm{O}$ mesmo acontecendo com a espectrometria de massa. Os ensaios imunológicos serão, certamente mais utilizados na tecnologia dos lacticínios, quando estiverem disponíveis comercialmente anticorpos mais baratos e específicos.

\section{REFERÊNCIAS}

1. Beer, M.; Krause, I.; Stapf, M.; Schwarzer, C.; Klostermeyer, H.; Z. Lebensm. Unters Forsch. 1996, 203, 21.

2. Cattaneo, T.M.P.; Nigro, F.; Greppi, G.F.; Milchwissenschaft 1996, 51, 616.

3. Haza, A.I.; Morales, P.; Martín, R.; García, T.; Anguita, G.; González, I.; Rodríguez, E.; Sanz, B.; Hernández, P.E.; J. Agric. Food Chem. 1996, 44, 1756.

4. Plath, A.; Krause, I.; Einspanier, R.; Z. Lebensm. Unters Forsch. A. 1997, $205,437$.

5. Lo, C.G.; Bastian, E.D.; J. Dairy Sci. 1998, 81, 16.

6. Greenberg, R.; Dower, H.J.; J. Agric. Food Chem. 1986, 34, 30.

7. Recio, I.; Amigo, L.; López-Fandiño, R.; J. Chromatogr. Biomed. Sci. Appl. 1997, 697, 231.

8. Recio, I.; Frutos, M. de; Olano, A.; Ramos, M.; J. Agric. Food Chem. 1996, $44,3955$.

9. Ramos, M.; Bulletin 181 FIL_IDF. 1984.

10. Colmenar, M.L.; Carballido, A.; Garcia-Olmedo, R.; Anal. Bromatol. 1965 , $17,389$.

11. Faria, M.A.; Ferreira, M.A.; Rev. Port. Farm. 1999, XLIV, 31

12. Mendes, E.; Faria, M.A.P.; Ferreira, I.M.P.L.V.O.; Pinho, O.; Ferreira, M.A.; $9^{a s}$ Jornadas de Analisis Instrumental, Barcelona, Espanha, 1999.

13. Mendes, E.; Faria, M.A.P.; Ferreira, I.M.P.L.V.O; Ferreira, M.A.; $4^{o}$ Encontro de Química dos Alimentos, Coimbra, Portugal, 1999.

14. Ramos, M.; Martinez-Castro, I.; Le lait 1976, 56, 164.

15. Vanbelle, M.; Vervack, W.; Foulon, M.; Lait 1978, 58, 245.

16. Sadini, V.; Il Latte 1963, 37, 933.

17. Urbanke, W.; Luf, W.; Brandl, E.; Z. Lebensm. Unters Forsch. 1992, 195 , 137.

18. Kaminarides, S.E.; Anifantakis, E.M.; J. Dairy Res. 1993, 60, 495.

19. Furtado, M.M.; J. Dairy Sci. 1983, 66, 1822.

20. Amigo, L.; Ramos, M.; Martin-Alvarez, P.J.; J. Dairy Sci. 1991, 74, 1482.

21. Mayer, W.; Hörtner, H.; Electrophoresis 1992, 13, 803.

22. Malin, E.L.; Basch, J.J.; Shieh, J.J.; Sullivan, B.C.; Holsinger, V.H.; J. Dairy Sci. 1994, 77, 2199. 
23. Casper, J.L.; Wendorff, W.L.; Thomas, D.L.; J. Dairy Sci. 1998, 81, 3117.

24. Basch, J.J.; Douglas Jr., F.W.; Procino, L.G.; Holsinger, V.H.; Farrell Jr., H.M.; J. Dairy Sci. 1985, 68, 23.

25. Strange, E.D.; Malin, E.L.; van Hekken, D.L.; Basch, J.J.; J. Chromatogr 1992, 624, 81 .

26. Grappin, R.; Ribadeau-Dumas, B. Em Advanced Dairy Chemistry - 1: Proteins; Fox, P.F., ed.; Blackie Academic \& Professional: London, 1992, p. 1-62.

27. Chen, F.-T.A.; Zang, J.-H.; J. AOAC Int. 1992, 75, 905.

28. Riel, J.v.; Olieman, C.; Electrophoresis 1995, 16, 529.

29. Cartoni, G.; Coccioli, F.; Jasionowska, R.; Masci, M.; J. Chromatogr., A 1999, 846, 135.

30. Pinto, F.C.; J. Dairy Res. 1966, 33, 129.

31. Durand, M.; Meusnier, M.; Delahaye, J.; Prunet, P.; Boll. Ac. Vet. 1974, 47, 247.

32. García, T.; Martin, R.; Rodríguez, E.; Hernaández, P.E.; Sanz, B.; J. Dairy Res. 1989, 56, 691.

33. García, T.; Martín, R.; Rodríguez, E.; Morales, P.; Hernández, P.E.; Sanz, B.; J. Dairy Sci. 1990, 73, 1489.

34. García, T.; Martín, R.; Rodríguez, E.; Azcona, J.I.; Sanz, B.; Hernández, P.E.; J. Food Prot. 1991, 54, 366.

35. Richter, W.; Krause, I.; Graf, C.; Sperrer, I.; Schwarzer, C.; Klostermeyer, H.; Z. Lebensm. Unters Forsch. A 1997, 204, 21.

36. Targowski, S.P.; J. Dairy Sci. 1983, 66, 1781.

37. Van Hooydonk, A.C.M.; Olieman, C.; Netherlands Milk and Dairy Journal 1982, 36, 153

38. Olieman, C.; van Riel, J.A.M.; Netherlands Milk and Dairy Journal 1989, $43,171$.
39. Léonil, J.; Mollé, D.; J. Dairy Res. 1991, 58, 321

40. Outinen, M.; Tossavainen, O.; Syväoja, E.-L.; Korhonen, H.; Milchwissenschaft 1995, 50, 570.

41. Mulvihll, D.M. Em Advanced Dairy Chemistry - 1: Proteins; Fox, P.F., ed.; Blackie Academic \& Professional: London, 1992; p. 369-404.

42. Ashoor, S.H.; Stiles, P.G.; J. Chromatogr. A 1987, 393, 321.

43. Recio, I.; Olieman, C.; Electrophoresis 1996, 17, 1228.

44. Ferreira, I.M.P.L.V.O.; Mendes, E.; Ferreira, M.A.; Anal. Sci. 2001, 17, 499.

45. López-Fandiño, R.; Olano, A.; Corzo, N.; Ramos, M.; J. Dairy Res. 1993, $60,339$.

46. Erbersdobler, H.F.; Dehn, B.; Nangpal, A.; Reuter, H.; J. Dairy Res. 1987, $54,147$.

47. Léonil, J.; Mollé, D.; Fauquant, J.; Maubois, J.L.; Pearce, R.J.; Bouhallab, S.; J. Dairy Sci. 1997, 80, 2270.

48. Léonil, J.; Mollé, D.; Gaucheron, F.; Arpino, P. Guénot, P.; Maubois, J.L; Lait 1995, 75, 193.

49. Trujillo, A.J.; Casals, I.; Guamis, B.; J Chromatogr. A 2000, 870, 371.

50. Trujillo, A.J.; Casals, I.; Guamis, B.; J Dairy Sci. 2000, 83- 11.

51. Ferranti, P.; Malorni A.; Nitti, G.; Laezza, P.; Pizzano, R.; Chianese, L.; Addeo, F.; J. Dairy Res. 1995, 62, 281.

52. Visser, S.; Slangen, C.J.; Lagerwerf, F.M.; Van Dongen, W.D.; Haverkamp J.; J Chromatrogr., A 1995, 711, 141.

53. Chianese, L.; Garro, G.; Nicolai, M.A.; Mauriello, R.; Ferranti, P.; Pizzano, R.; Cappuccio, U.; Laezza, P.; Addeo, F.; Ramuno, L.; Rando, A.; Rubino, R.; Lait 1993, 73, 533.

54. Burr, R.; Moore, C.H.; Hill, J.P.; Milchwissenschaft 1996, 51, 488. 